\title{
Proposal for a short version of an international questionnaire to detect bullying: adaptation to Argentine Spanish language and exploratory factor analysis
}

\author{
M. Florencia Herrera Bornes ${ }^{a}$ (D) , Diego Terceiro ${ }^{a}$ (D), Fernando Vázquez Peña ${ }^{a}$ (D), \\ Natividad Burdisso ${ }^{a}$ (D), Sergio Terrasa ${ }^{a, b}$ (D)
}

ABSTRACT
Introduction. Bullying encompasses intentional
intimidation, abuse, and physicalorpsychological
harassment behaviors by a student (bully) against
another student (victim) repeatedly. It includes
physical and verbal abuse, social exclusion, and
cyberbullying. Victims miss school more often
and have a higher risk for somatic symptoms,
anxiety, depression, and suicide. Although the
Adolescent Peer Relations Instrument (APRI)
is a bullying screening questionnaire (19 items)
validated inSpainin 2016, there was novalidated
instrument available in Argentina.
Objective. To obtain a short version adapted to Objective. To obtain a short version adapted to
Argentine Spanish of the APRI. Population and method. The APRI, a questionnaire to screen for bullying among adolescents, was cross-culturally adapted to Argentine Spanish language and then questionnaire items were reduced by a mathematical process (exploratory factor analysis) and a conceptual process (expert committee). Participants were adolescents aged 13-17 years who were attending secondary public schools in the city of Boulogne Sur Mer, San Isidro, province of Buenos Aires.

Results. A short questionnaire version made up of 14 items divided into 2 dimensions (physical abuse and social and verbal victimization) was obtained.

Conclusions. The resulting short questionnaire is semantically equivalent to the original version and also has adequate apparent and content validity.

Key words: bullying, surveys and questionnaires, adolescent, Adolescent Peer Relations Instrument.

http: / / dx.doi.org/10.5546/ aap.2022.eng.14

M. Florencia Herrera Bornes:

mariaflorenciaherrera bornes@gmail.com

Funding:

Family and Community

Medicine Service of

Hospital Italiano de

Buenos Aires.

Conflict of interest:

None.

Received: 10-15-2020

Accepted: 7-2-2021

\section{INTRODUCTION}

Peer bullying ${ }^{1}$ refers to intentional intimidation, abuse, and physical or psychological harassment behaviors by a student against another student repeatedly over time and for the purpose of hurting, humiliating, and isolating a victim who does not know and / or cannot defend themselves. ${ }^{2}$ There are different types of bullying: physical, verbal, social exclusion, and cyberbullying. ${ }^{3}$

Bullying victims tend to miss school more often and have a poorer academic performance, ${ }^{4-6}$ more somatic symptoms, and a higher incidence of mood disorders, ${ }^{7-11}$ which may carry on to adulthood. It also increases the risk for suicide ideation ${ }^{12}$ and / or attempt ${ }^{13}$ and is associated with a worse social and future job insertion..$^{14,15}$

According to global data, $11 \%$ of adolescents admitted that they had bullied a fellow student, $13 \%$ stated that they had been bullied, and $4 \%$, that they had played both roles, ${ }^{16}$ which is consistent with what has been documented in Latin America. ${ }^{17}$

Although some data is available in Argentina, ${ }^{18,19}$ they were documented using screening instruments that had not been locally validated, probably because most structured questionnaires were developed using process of little methodological quality $^{20}$ or are very extensive. An exception to this is the Adolescent Peer Relations Instrument (APRI), a questionnaire to detect bullying made up of 19 items $^{21}$ that has been validated in Spain..$^{22}$

To prevent bullying and its 
consequences, it is necessary to have reliable data obtained using instruments that have been crossculturally adapted to Argentine Spanish and that can be easily and rapidly completed. For this reason, we started the validation process for a short version of the APRI so that it could be implemented in a practical manner to screen for bullying in Argentine schools.

\section{OBJECTIVE}

To obtain a short version cross-culturally adapted to Argentine Spanish of the APRI questionnaire to detect bullying.

\section{POPULATION AND METHODS Design}

Cross-cultural adaptation of a questionnaire to Argentine Spanish, followed by a conceptual process of item reduction and apparent and content validation (expert committee), and an exploratory factor analysis (EFA) ${ }^{23}$ using a crosssectional study.

\section{Population}

Adolescents aged 13-17 years with a middle and low socioeconomic level attending secondary schools no. 20 and no. 24 in Boulogne Sur Mer, San Isidro, province of Buenos Aires. These are public schools located in the influence area of Centro de Salud San Pantaleón, where the study authors practice. Both study sites agreed to collaborate and all students who met the inclusion criteria were invited to participate.

\section{Instrument}

The Spanish version ${ }^{24}$ of the APRI includes a physical victimization dimension (6 items), a verbal/social victimization dimension (12 items), and an item about cyberbullying. Each item contains an ordinal scale to assess the frequency of victimization situations. The sum of values in each item results in an overall score. An overall score of 2.1 (95\% confidence interval: 1.7-2.5) correlates to null bullying levels; 6.9 (6.1-6.9), to moderate bullying levels; and 16.7 (14.7-18.7), to severe bullying levels. Reliability -overall and in each sub-scale- is satisfactory (between 0.85 and 0.94).

\section{Cross-cultural adaptation of the APRI ${ }^{25,26}$}

a) Adaptation to Argentine Spanish language by 3 separate investigators who were native speakers.

b) Reconciliation of the 3 adaptations and comparison of the resulting version with the original instrument, assessing any discrepancy in how questions were written and conceptual, semantic, and content equivalences.

c) Recorded cognitive interviews with 10 adolescents ( 5 boys and 5 girls) to identify comprehension problems.

d) Review of interview results, development of the final version after looking for any grammar or spelling mistake, and description of decisions made during the process.

\section{Assessment of construct validity and reduction of instrument items by maintaining the most representative items in each dimension}

The resulting version was administered to a new sample of adolescents. Two investigators attended the school during class hours. After being introduced by the responsible teacher, they explained the questionnaire to each class for 5 minutes and obtained the written and signed informed consent from each student. The questionnaires were hand-delivered and students had 10 minutes to complete them individually and on their own. They had to attach their first and last names in the questionnaire sheet so that if any of them obtained a score indicating that they might be a bullying victim, school authorities could be warned. Investigators were available to answer any question about how to complete the questionnaire. Once completed, each student placed the questionnaire in an opaque envelope to keep answers confidential from the rest of their fellow students.

An $\mathrm{EFA}^{23}$ was done based on these answers to document if the questionnaire's mathematical behavior was compatible with its conceptual organization. Internal validity was assessed using extraction methods (analysis of principal components technique) and rotation techniques (oblimin with Kaiser normalization) ${ }^{23}$ with the SPSS $^{\circledR}$ software.

It is worth noting that the original objective was to perform a confirmatory factor analysis and that, for models containing up to 7 latent variables with low factor loads and less than 3 variables per construct, Hair $^{27}$ recommends having at least 150 observations and also describes the need to increase the sample size when using ordinal variables and/or variables without a normal distribution. For these reasons, 300 adolescents were initially considered to be invited. However, the closing of schools established by the Executive Power $^{28}$ due to the COVID-19 pandemic made it 
impossible to reach such sample size; therefore, we decided to perform an EFA ${ }^{23}$, which is a more economical technique in terms of sample size. With an EFA, and as stated by Streiner, ${ }^{29}$ having 5 observations per questionnaire item is enough, as long as there are at least 100.

A group of experts was then summoned, made up of 2 physical education teachers, 1 child and adolescent psychologist, 1 family physician, and 2 experts on questionnaires. This group modified the text and/or removed items with factor loads that were in conflict with their conceptual representation or that collected redundant information already obtained through other items.

\section{Ethical aspects}

Student participation was voluntary and was preceded by a process to obtain a written and signed informed consent. Students were assured that data would remain confidential and were given a document with resources they could use to seek help in case of suffering bullying. If bullying was suspected (questionnaire score above 6.1), school authorities were notified. The study was developed in accordance with national and provincial regulations on human health research, Ministry Resolution no. 1480/2011, the Declaration of Helsinki, as amended, and Law No. 25326 for Personal Data Protection.

The protocol was approved (No. 3831) by the Research Protocol Ethics Committee of Hospital Italiano de San Justo.

\section{RESULTS}

First stage of cross-cultural adaptation of the long questionnaire version to Argentine Spanish language

Comprehension difficulties were detected during the cognitive interviews so "several times" was replaced with "often" and "constantly" with "always." In addition, in item 18, we also changed the Spanish term used for "nicknames" for a more local term (Table 1).

\section{Exploratory analysis of the resulting} questionnaire's construct validity, second stage of cross-cultural adaptation and reduction of instrument items by maintaining the most representative items in each dimension

The questionnaire was administered to a sample of 100 students older than 13 years (mean age: 14 years, $52 \%$ were males). After the EFA rotation, items showed saturation levels between 0.85 and 0.01 (Table 2).

The first factor accounts for the social and/ or verbal victimization (SVV) dimension and the second one, for the physical victimization (PV) dimension. As observed in Table 2, 13 out of the 19 items showed the psychometric behavior expected for the type of information collected. However, and as observed in Spain, item 2 (They push me), which is conceptually part of the PV dimension, showed a higher saturation (0.44) in the SVV factor, with a very low load (0.01) in the PV factor. Item 8 (They bump into me to bother me when they pass by me) also showed a saturation of 0.38 in the SVV factor and 0.003 in the PV factor.

TABLE 1. Modifications introduced during the cross-cultural adaptation into Argentine Spanish of the APRI questionnaire to screen for peer bullying following cognitive interviews with a sample of adolescents and the expert group discussion

\begin{tabular}{|c|c|c|}
\hline \multirow[t]{2}{*}{ Modifications } & \multicolumn{2}{|c|}{ Version of the instrument } \\
\hline & validated in Spain & cross-culturally adapted in Argentina \\
\hline Item $2^{\mathrm{a}}$ & They push me to bother me & They push me to hurt me \\
\hline Item $18^{b, c}$ & $\begin{array}{c}\text { They give me motes (nicknames) } \\
\text { I don't like }\end{array}$ & $\begin{array}{c}\text { They give me apodos (nicknames) } \\
\text { I don't like }\end{array}$ \\
\hline Scale options ${ }^{\mathrm{b}}$ & $\begin{array}{l}\text { Several times } \\
\text { Constantly }\end{array}$ & $\begin{array}{l}\text { Often } \\
\text { Always }\end{array}$ \\
\hline
\end{tabular}

\footnotetext{
a Modification introduced by the expert group.

b Modification made based on cognitive interviews with adolescents.

${ }^{\mathrm{c}}$ Item removed from the questionnaire by the expert group.
} 
Other items were also expected to have a more relevant load in the SVV factor, but showed a stronger load in the PV factor. Those were items 1 (They tease me), 13 (They mock me saying unpleasant things about me), 14 (They tell lies about me to hurt me), and 18 (They give me nicknames I don't like), which showed saturation values of $0.64,0.85,0.44$, and 0.50, respectively, in the PV factor and which clearly represent bullying actions corresponding to the SVV dimension.

Table 2 describes the EFA results.

Once identified, items with a lower load in each dimension or that loaded a factor different than expected were discussed by the expert group. Based on conceptual redundancy, cultural representativeness of each item, and psychometric behavior, it was decided to remove 5 items: 1 from the PV dimension and 4 from the SVV dimension. The questionnaire included only the 14 items shown in bold in Table 2.

The expert group decided to remove item 8 (They bump into me to bother me when they pass by $m e)$ because, in addition to showing an inadequate factor load (SVV), experts indicated that, in this setting, this type of behavior is very commonly interpreted as a prank to show camaraderie and complicity than as a bullying action. The expert group also decided to rewrite item 2 (They push me to bother me) from this dimension to They push me to hurt me to keep it in the short questionnaire version because they argued that pushing is very common among adolescents and that it is not always construed as an aggression. For this reason, they decided to specify that the action's purpose was to hurt someone so that the subjective feeling of the victim was captured.

The SVV dimension included 13 items $(1,3,4$, $6,7,9,11,12,13,14,17,18$, and 19). In this case, the expert group decided to remove 4 items $(1,13$, 14 , and 18) because they did not load into the SVV factor, as expected in relation to psychometric behavior. Another reasoning to remove these items is that 3 of them-1 (They tease me), 13 (They mock me saying unpleasant things about me), and 14 (They tell lies about me to hurt me)—overlap with 3 other items that were maintained because such concepts are represented in other questions, such as items 4 (They say mean things about me), 11 (They

TABLE 2. Result of the exploratory factor analysis using a principal component analysis as an extraction method and oblimin with Kaiser normalization as a rotation method, for the cross-cultural adaptation into Argentine Spanish of the APRI questionnaire to screen for peer bullying

\begin{tabular}{lcc}
\hline Items & \multicolumn{2}{c}{ Dimensions } \\
\hline & Verbal/social & Physical \\
\hline They tease me. & 0.293 & 0.649 \\
They push me to bother me. & 0.447 & 0.019 \\
They won't be friends with me because someone/some people do not like me. & 0.433 & 0.341 \\
They say mean things about me. & 0.8 & 0.044 \\
They hit me. & 0.312 & 0.655 \\
Someone ignores me when he/she is with their friends. & 0.349 & 0.084 \\
They have fun playing nasty tricks on me or joking about me. & 0.43 & 0.344 \\
They bump into me to bother me when they pass by me. & 0.385 & 0.003 \\
They get others to not speak to me and turn them against me. & 0.77 & 0.004 \\
They damage my belongings on purpose. & 0.132 & 0.396 \\
They say unpleasant things about my looks. & 0.788 \\
I am not invited when they get together or go to parties or the homes & 0.005 \\
of other students because someone who is going does not like me. & 0.687 \\
They mock me saying unpleasant things about me. & 0.132 \\
They tell lies about me to hurt me. & 0.076 \\
They throw objects at me to bother me. & 0.013 \\
They threaten to hit or hurt me. & 0.26 \\
They exclude me from activities, games or meetings on purpose. & 0.635 \\
They give me nicknames I don't like. & 0.403 \\
They've harassed me through social networks (Instagram, Facebook, WhatsApp, etc.) & 0.505 & 0.064 \\
\hline
\end{tabular}

The items in bold were included in the short questionnaire version. 
say unpleasant things about my looks), and 7 (They have fun playing nasty tricks on me or joking about me), which did show the expected psychometric behavior in the EFA.

Experts also decided to remove item 18 (They give me nicknames I don't like) because, in addition to showing an ambiguous psychometric behavior (mildly higher load in the PV than in the SVV factor), the information it collects is already represented by items 4 and 11 (see above). Furthermore, and although the question was clearly formulated to mean "nicknames I don't like," in our setting it is very common to use nicknames without bullying connotations, so the expert group interpreted that the psychometric behavior different from what was expected may be explained by the difficult interpretation of the potentially aggressive connotation of a nickname used to victimize the target subject.

The expert group considered that the version resulting from this process had an adequate apparent and content validity.
Resulting final version of the questionnaire

Based on the results, the proposed short version is made up of 14 items divided into 2 dimensions: PV (items 2, 5, 10, 15, and 16) and $\operatorname{SVV}(3,4,6,7,9,11,12,17$, and 19) (Table 3). (Questionnaire in Word format.)

\section{DISCUSSION}

This study describes the EFA results of the cross-culturally adaptation into Argentine Spanish language of the APRI questionnaire to detect bullying among adolescents, originally developed in Australia and subsequently validated in Spain. ${ }^{24}$

The instrument achieved apparent validity -both experts and users agreed that the questionnaire measures the targeted variablesand content validity -it measures the different construct dimensions-. However, the main limitation of this study is that it did not document the construct validity of the adapted version using a confirmatory factor analysis, as anticipated in the

TABLE 3. Final version of the cross-cultural adaptation and reduced number of questionnaire items

\begin{tabular}{|c|c|c|c|c|c|}
\hline During this academic year, in my school: & Never & Sometimes & Often & Many times & Always \\
\hline \multicolumn{6}{|l|}{ 1. They push me to hurt me. } \\
\hline \multicolumn{6}{|l|}{$\begin{array}{l}\text { 2. They won't be friends with me because someone/ } \\
\text { some people do not like me. }\end{array}$} \\
\hline \multicolumn{6}{|l|}{ 3. They say mean things about me. } \\
\hline \multicolumn{6}{|l|}{ 4. They hit me. } \\
\hline \multicolumn{6}{|l|}{$\begin{array}{l}\text { 5. Someone ignores me when he/she is with } \\
\text { their friends. }\end{array}$} \\
\hline \multicolumn{6}{|l|}{$\begin{array}{l}\text { 6. They have fun playing nasty tricks on me } \\
\text { or joking about me. }\end{array}$} \\
\hline \multicolumn{6}{|l|}{$\begin{array}{l}\text { 7. They get others to not speak to me and turn } \\
\text { them against me. }\end{array}$} \\
\hline \multicolumn{6}{|l|}{ 8. They damage my belongings on purpose. } \\
\hline \multicolumn{6}{|l|}{ 9. They say unpleasant things about my looks. } \\
\hline \multicolumn{6}{|l|}{$\begin{array}{l}\text { 10. I am not invited when they get together or go to } \\
\text { parties or the homes of other students because } \\
\text { someone who is going does not like me. }\end{array}$} \\
\hline \multicolumn{6}{|l|}{ 11. They throw objects at me to bother me. } \\
\hline \multicolumn{6}{|l|}{ 12. They threaten to hit or hurt me. } \\
\hline \multicolumn{6}{|l|}{$\begin{array}{l}\text { 13. They exclude me from activities, games } \\
\text { or meetings on purpose. }\end{array}$} \\
\hline $\begin{array}{l}\text { 14. They've harassed me through social networks } \\
\text { (Instagram, Facebook, WhatsApp, etc.) }\end{array}$ & & & & & \\
\hline
\end{tabular}


original study design, due to the closing of schools established in relation to the COVID-19 pandemic, which prevented us from getting more students to complete the questionnaire. Therefore, the study was carried out using the questionnaires collected initially.

The instrument proposed here has the advantage of already being validated in Spain, and now there is also an adaptation to Argentine Spanish available, which includes modifications aimed at improving its psychometric behavior at a local level.

A limitation of the APRI is that, as in the "social acceptance" dimension of the Kidscreen-52 questionnaire, ${ }^{30}$ it focuses only on victimization. It is worth noting that bullying is a systemic process that involves different actors because, in addition to victims and bullies, passive witnesses of violent situations and school authorities also take part. ${ }^{31}$ In this regard, the questionnaire proposed here will be useful to detect bullying victims because it asks adolescents about their personal experience first-hand. However, a limitation is that it does not collect information about the other bullying participants (bullies, witnesses and / or school authorities). This aspect should be taken into consideration if used in the future, both in prevalence studies and the design of prevention programs.

To conclude, we believe that, based on this first cross-cultural adaptation into Argentine Spanish, we have obtained a short questionnaire that is semantically equivalent to the original instrument and has an adequate apparent and content validity. Still ahead lies a confirmatory factor analysis with a new sample and an assessment to determine whether the Argentine version is sensitive to detect changes in bullying levels, for example, following the implementation of local prevention programs.

\section{Acknowledgments}

To Lic. Julieta Muñoz and Professors Ivana Frangi and Carlos Nievas for their participation as experts to analyze and agree on the changes made to the questionnaire.

\section{REFERENCES}

1. Olweus D. Aggression in the Schools: Bullies and Whipping Boys. Washington: Hemisphere Publishing Corporation; 1978.

2. Sociedad Española de Medicina Familia y Comunitaria (semFYC). Tratado De Medicina Familiar Y Comunitaria. $2^{\text {da }}$ ed. Madrid: Panamericana; 2012.

3. García Continente X, Pérez Giménez A, Nebot Adell M. Factores relacionados con el acoso escolar (bullying) en los adolescentes de Barcelona. Gac Sanit. 2010; 24(2):103-8.

4. Wolke D, Woods S, Bloomfield L, Karstadt L. Bullying involvement in primary school and common health problems. Arch Dis Child. 2001; 85(3):197-201.

5. Bond L, Carlin JB, Thomas L, Rubin K, Patton G. Does bullying cause emotional problems? A prospective study of young teenagers. BMJ. 2001; 323(7311):480-4.

6. Ramirez M, Wu Y, Kataoka S, Wong M, et al. Youth violence across multiple dimensions: a study of violence, absenteeism, and suspensions among middle school children. J Pediatr. 2012; 161(3):542-6.e2.

7. Yen C-F, Yang P, Wang P-W, Lin H-C, et al. Association between school bullying levels/types and mental health problems among Taiwanese adolescents. Compr Psychiatry. 2014; 55(3):405-13.

8. Weng X, Chui W, Liu L. Bullying Behaviors among Macanese Adolescents-Association with Psychosocial Variables. Int J Environ Res Public Health. 2017; 14(8):887.

9. Ford R, King T, Priest N, Kavanagh A. Bullying and mental health and suicidal behaviour among 14- to 15-year-olds in a representative sample of Australian children. Aust N Z J Psychiatry. 2017; 51(9):897-908.

10. Bhatta MP, ShakyaS, Jefferis E. Association of being bullied in school with suicide ideation and planning among rural middle school adolescents. J Sch Health. 2014; 84(11):731-8.

11. Fahy AE, Stansfeld SA, Smuk M, Smith NR, et al. Longitudinal Associations Between Cyberbullying Involvement and Adolescent Mental Health. J Adolesc Health. 2016; 59(5):502-9.

12. Barzilay S, Brunstein Klomek A, Apter A, Carli V, et al. Bullying Victimization and Suicide Ideation and Behavior Among Adolescents in Europe: A 10-Country Study. J Adolesc Health. 2017; 61(2):179-86.

13. Romo ML, Kelvin EA. Impact of bullying victimization on suicide and negative health behaviors among adolescents in Latin America. Rev Panam Salud Pública. 2016; 40(5):34755.

14. Walton M. Adult Bullying: Perpetrators and Victims. J Manag Psychol. 1998; 13(1/2):122.

15. Smith PK, Singer M, Hoel H, Cooper CL. Victimization in the school and the workplace: are there any links? $\mathrm{Br} J$ Psychol. 2003; 94(Pt 2):175-88.

16. Craig W, Harel-Fisch Y, Fogel-Grinvald H, Dostaler S, et al. A cross-national profile of bullying and victimization among adolescents in 40 countries. Int J Public Health. 2009; 54(Suppl 2):216-24.

17. Marín-Martínez A, Reidl Martínez LM. Validación psicométrica del cuestionario "así nos llevamos en la escuela" para evaluar el hostigamiento escolar (bullying) en primarias. RMIE. 2013; 18(56):11-36.

18. Moreno C. El Fenómeno bullying en adolescentes mendocinos. Asociación Argentina de Ciencia del comportamiento. XV Reunión Nacional IV reunión internacional. 26-28 de agosto de 2015. San Miguel de Tucumán. 2015.

19. Durán L, Scherñuk Schrok JC, Panizoni SP, Jouglard EF, et al. Intimidación escolar: concordancia entre la percepción de los cuidadores y sus hijos. Arch Argent Pediatr. 2017; 115(1):35-42.

20. Vera Giraldo CY, Vélez CM, García HI. Medición del bullying escolar: Inventario de instrumentos disponibles en idioma español. PSIENCIA. 2017; 9(1):31.

21. Parada R. Adolescent peer Relations Instrument: A Theoretical an Empirical Basis for the Measurement of Participant Roles in Bullying and Victimization of Adolescence: An Interim Test Manual and a Research Monograph. Penrith South, DC, Australia: SELF. 2000.

22. Gascón-Cánovas JJ, Russo de Leon JR, Cózar Fernández 
A, Heredia Calzado JM. Adaptación cultural al español y baremación del Adolescent Peer Relations Instrument (APRI) para la detección de la victimización por acoso escolar: Estudio preliminar de las propiedades psicométricas. An Pediatr. 2017; 87(1):9-17.

23. Wild D, Grove A, Martin M, Eremenco S, et al. Principles of Good Practice for the Translation and Cultural Adaptation Process for Patient-Reported Outcomes (PRO) Measures: Report of the ISPOR Task Force for Translation and Cultural Adaptation. Value Health. 2005; 8(2):94-104.

24. Lloret-Segura S, Ferreres-Traver A, Hernández-Baeza A, Tomás-Marco I. El análisis factorial exploratorio de los ítems: una guía práctica, revisada y actualizada. Anal Psicol. 2014; 30(3):1151-69.

25. Ramada-Rodilla JM, Serra-Pujadas C, Delclós-Clanchet GL. Adaptación cultural y validación de cuestionarios de salud: revisión y recomendaciones metodológicas. Salud Pública Méx. 2013; 55(1):57-66.
26. Streiner D, Norman GR. Health Measurement Scales: A practical guide to their development and use. $4^{\text {th }}$ ed. Oxford: Oxford Univerity Press; 2008.

27. HairJF, Black W, Babin BJ, Anderson RE. Multivariate Data Analysis. $7^{\text {th }}$ ed. Hoboken: Pearson; 2009.

28. Gómez AG. El Decreto 297/2020 de aislamiento social preventivo y obligatorio: análisis constitucional e implicancias penales de su incumplimiento. Rev Derecho Penal Criminol. 2020; 10(4)3-13.

29. Streiner DL. Figuring out factors: the use and misuse of factor analysis. Can J Psychiatry. 1994; 39(3):135-40.

30. BerraS, TebéC, Esandi M, CarignanoC. Fiabilidad y validez del cuestionario KIDSCREEN-52 para medir calidad de vida relacionada con la salud para población argentina de 8 a 18 años. Arch Argent Pediatr. 2013; 111(1):29-36.

31. Trautmann MA. Maltrato entre pares o "bullying": Una visión actual. Rev Chil Pediatr. 2008; 79(1):13-20. 